\title{
Social Media as an Information Source in Finance: Evidence from the Community of Financial Market Professionals in Poland
}

Andrej Cwynar. University of Economics and Innovation, Poland, andrzej.cwynar@wsei.lublin.pl

Wiktor Cwynar. University of Economics and Innovation, Poland, wiktor.cwynar@wsei.lublin.pl

Robert Pater. University of Information Technology and Management, Poland, rpater@wsiz.rzeszow.pl

Kamil Filipek. Maria Curie-Skłodowska University, Poland, kfilipek@umcs.pl

\begin{abstract}
Social media has become a source of information for individuals making decisions in financial institutions worldwide. As a part of Business Intelligence systems, platforms such as Facebook, Twitter, or LinkedIn provide financial market professionals with a magnitude of market data — for example, stock price expectations, customer insights, and market sentiment. Based on 415 survey responses of financial market professionals in Poland (purposive sample), this study examines factors behind social media usage in financial institutions. We found that decision-makers representing these institutions seldom use social media for job-related purposes. However, the professionals from institutions that manage more diversified asset portfolios and hold the most risky assets in the portfolios, are more likely to use social media for information purposes. We also found that the value of assets does not affect the use of social media for information purposes among financial market professionals in Poland. This implies that representatives of certain types of financial institutions are more inclined to use social media for professional purposes. Our study offers an insight into the variables that best explain the decision to monitor social media content by financial market professionals. Thus, it can provide a basis of recommendations aiming to enhance the market for business information.
\end{abstract}

Keywords: social media, financial market professionals, information needs, decision-making. 


\section{INTRODUCTION}

Decisions made in financial markets are usually preceded by the analysis of information collected from diverse sources considered as reliable and indispensable (Ravichandran and Lertwongsatien, 2005). This may suggest that information has a specific value verified by outcomes of decisions made by the market participants. However, in a highly competitive environment such as financial markets, decision-making has become very complicated due to a large amount of information generated by multiple sources. Particularly, the advent of Internet and online communication has flooded markets with a magnitude of information, which has required new regulations and has put additional pressures on decision-makers to select value from 'data smog' (Shenk, 1998). As a consequence, financial market professionals face a number of info-dilemmas, which are further enhanced by the expansion of social media platforms-such as Twitter, Facebook, or LinkedIn-and complementing traditional information sources - such as TV, radio and printed press.

Nowadays, financial market professionals make decisions in volatile, irrational, and quasi-predictable market conditions. There are studies reporting that the information included in the professional analytical reports is not significantly discounted by financial market participants due to their methodological discretion and resulting ambiguity (Keller and Pastusiak, 2016). In such settings, social media appears to be a specific tool ensuring access to diverse market information needed at any operational level of modern financial institutions. On the one hand, it is found that social media helps to predict future stock returns (Bollen et al., 2011; Chen et al., 2014), manage compliance policies (Chanda and Zaorski, 2013), or forecast firm equity value (Luo et al., 2013). On the other hand, information acquired from social platforms can be low-quality, incomplete or fake (Power and Phillips-Wren, 2011).

It is therefore vague whether financial market professionals use social media occasionally or systematically with less or more defined purposes in such competitive environment like the finance industry. Cao et al. (2012) found that social media may enhance work performance of software professionals by fostering trust and enabling knowledge transfer. In the same fashion, Leftheriotis and Giannakos (2014) analysed the social media use among employees in the insurance industry. They established that two out of three insurance professionals make occasional use of social media for job-related purposes. Importantly, employees with higher use of social media in work were more productive. 
Schniederjans et al. (2013) suggest that financial performance of companies may be enhanced by purposive use of social media by employees. They found that impression management strategy had at least partial, positive impact on financial performance of the pharmaceutical firms.

The crucial question that so far has not been extensively studied is what factors encourage financial market professionals to use social media as an information source. Thus, the main objective of this study is to examine the determinants of social media use in financial companies. In doing so, we focus on company features (e.g. the size, level of risk and diversification of assets, employees' professional experience) as potential factors affecting respondents' decision to select social media as an information source. Consequently, the following research questions are pursued: (i) Why do financial market professionals use social media? (ii) What is the impact of company features-for example, assets' value, diversity and risk —on social media use by financial market professionals? (iii) Does job experience of financial market professionals influence their use of social media for informational purposes?

The contribution of this paper is twofold. Firstly, we contribute to the existing literature on decision making by exploring the usage of social media among financial professionals (analysts, managers, directors and executives). Secondly, we propose and empirically test factors that may influence the decision to use social media by financial professionals. We specifically evaluate the impact of the number, type and value of assets in selected companies.

We started from the assumption that finding answers to these questions can help to customize the supply of software solutions converting textual data into useful information in order to cater for different needs of financial institutions, and hence to improve information efficiency of financial markets.

\section{SOCIAL MEDIA AS AN INFORMATION SOURCE}

There are many definitions of social media across literature. Usually, they refer to a variety of services, such as social networking sites (e.g., Facebook, LinkedIn), blogs, wikis, content communities (e.g., YouTube, Flickr, SlideShare), and virtual worlds (e.g., Second Life, World of Warcraft). Drawing from existing definitions and theories, it appears that social media has some common characteristics: (i) Web 2.0 philosophy (Kaplan and Haenlein, 2010), (ii) sharing (Fuchs, 2015; Meikle, 2016), (iii) social networks (Boyd and Ellison, 2008), (iv) new forms of socialisation (Obar and Wildman, 2015). All of these features make social media a 
potentially valuable source of information for financial market professionals making decisions at different operational levels. Particularly, by offering a wide range of market-related information, social media platforms can help decisionmakers manage diversity and risks associated with asset portfolios.

Over the last decade, social media has been recognised as a part of intelligence systems in contemporary business (Nair, 2011; Fan and Gordon, 2013). Banks, stockbrokers, insurers, governments etc., use social media to tackle frauds (Meijer and Thaens, 2013), adjust financial products (Chen et al., 2014), advertise services (Chanda and Zaorski, 2013), or identify market sentiment to optimise investment decisions (Bing et al., 2014). Some financial service companies use social media to gain back the trust and reputation destroyed by the 2007-2008 global financial crisis (Hobday and Charles, 2012), while others use it primarily to recognise new financial products delivered to customers via social media platforms. In 2012, Corporate Insight reported that $92 \%$ of financial services firms in the USA used Twitter for business purposes (Robehmed, 2012). According to Gnip (2014), a leading provider of social media data, SEC approval to use social media for market publication purposes was an impetus for many financial firms to use such platforms in order to optimise decision-making process. Greenwich Associates (2015) found that 79\% of 256 institutions from Europe, Asia-Pacific and the USA use social media for informational purposes. Institutional investors in the AsiaPacific are the biggest consumers of social media content due to lower availability of professional market data (e.g., Bloomberg terminals) in this region, as suggested by the authors of the report.

Kouri and Bowen (2015) report that financial professionals use social media to read market news and insights, share content relevant to their clients, monitor people (e.g. clients, prospects) and industry or promote business. LinkedIn was the most popular platform helping financial professionals to develop their expertise and expand business. The findings of $\mathrm{Hu}$ and Tripathi (2016) suggest that information available on social media does not overlap with information accessible through news media. Thus, social media are additional or complementary sources of news, rather than the substitutive information channel. Similarly, Dong et al. (2016) demonstrate that social media significantly contributes to financial fraud disclosure and delivers fraud predictions with a high rate of accuracy. They suggest that a combination of social media analytics (content analysis) with a set of financial indicators results in a high accuracy of fraud prediction (83.57\%). Zhang et al. (2016) propose a Degree of Social 
Attention (DSA) framework based on social media data to effectively capture abnormal stock returns. It has been established that DSA (based on posts, likes, comments etc.) contributes to price forecasting, risk management and asset pricing.

However, to the best of our knowledge, the relationship between social media use for informational purposes and a financial institution's asset portfolio-its size, structure and risk profile-has not been studied before. The linking of these two variables appears to be reasonable, as some prior studies showed that information is a desirable good (Grossman and Stiglitz, 1980; Tóth and Scalas, 2008), although partial information is not always rewarding (Kirchler, 2010). Business modelling in finance, including portfolio optimisation, credit scoring or risk prediction, requires effective processing of information inflowing from diverse sources. It is, therefore, assumed here that a financial company's characteristics, such as product offer, size and diversity of the asset portfolio, may have an impact on the informational needs of decision-makers in financial companies. Decisions are made in a given external and internal setting, but the ultimate goal is to find information helping to optimise operations on the market. It is, therefore, expected that the size of the asset portfolio - as measured by its value - and diversification of the portfolio, in terms of the number of asset types included in it, are positively associated with informational needs of financial institutions. Namely, companies with larger and more diversified asset portfolios require a higher volume of information delivered through multiple channels, including social media. As a consequence, the following hypotheses are proposed:

H1: The more sizable the assets are under the institution's management, the higher the inclination is to monitor social media as data and information sources.

H2: The more diversified the assets are under the institution's management, the higher the inclination is to monitor social media as data and information sources.

Yet, the size and diversity of an asset portfolio are not the only characteristics linked to the information needs of decision-makers in a contemporary finance industry. For example, policy makers in a company with a small and quite homogeneous portfolio of assets may have a huge demand for social media information, as they manage very risky instruments (Guiso and Jappelli, 2006). In other words, risks related to the assets may encourage decision-makers to search 
for additional information sources, such as social media platforms, in order to optimise the decision-making process on the financial market. Social media may optimise this process by reducing costs associated with risk management (Cumming and Hirtle, 2001), or more precisely, by mitigating side effects of information asymmetry (Arrow, 1985). Building on that, the following hypothesis is proposed:

H3: The more risky the assets are under the institution's management, the higher the inclination is to monitor social media as data and information sources.

Recent research suggests that CFOs are in the early stages of social media participation (Leadtail - Intacct, 2015). They engage in social media relations primarily for private purposes and are less interested than other C-suites executives in searching for business information. Drawing from the research in this area, it is possible that CFOs, relying on their professional experience, become overconfident (Barber and Odean, 2002) and perceive social media in terms of an additional information outlet rather than a primary source of information. As a consequence, it could be assumed that junior financial market professionals with poorer job experience will more likely use social media for business purposes due to their lower confidence. Accordingly, professional experience is understood here in terms of both the years of experience on current job position, and the years of experience in business analysis / asset management. Despite little research in this filed, the following hypothesis is proposed:

H4: Less experienced financial market professionals use social media as a data and information source more willingly than more experienced ones.

\section{DATA AND METHODS}

\subsection{Data Collection}

In order to reach financial market professionals, we prepared a specified list of financial companies operating in the Polish market. The list was prepared on the basis of Standard Industrial Classification codes and complemented with the organisations included on the list of financial institutions run by the Polish Financial Supervision Authority (Komisja Nadzoru Finansowego, 2016). However, continuous regulatory change in the Polish financial market affects the number of firms (sampling frame) considered as financial institutions. We found 
that some companies from our initial list were inactive or falling into bankruptcy. As a consequence, we were not able to establish a sampling frame from which a random sample could be drawn. In such dynamic economic environment the most reasonable solution is to use a purposive sample reflecting the market structure of a specific industry. Therefore, we used the official reports of the National Bank of Poland (NBP, 2016) as a reference for checking whether our sample credibly reflects the real structure of the financial market in Poland. Although the purposive sampling method does not yield the representativeness of results that could be projected to the entire population of financial professionals in Poland, there are studies showing that the non-probabilistic methods have similar levels of accuracy as probabilistic ones (Martinsson et al., 2013).The sample is detailed in Table 1 (the item 'Represented institutions').

Initially, 2,138 firms were identified in the commercial database provided by the market research company. Then, 4,800 talks were arranged with respondents from an identified population of firms, which led to 415 full interviews (ComputerAssisted Telephone Interviewing) with individuals making decisions related to financial products and services offered on the market. The survey was conducted between $25^{\text {th }}$ April and $6^{\text {th }}$ June of 2016.

\subsection{Models}

To explain the use of social media by the respondents for informational purposes $\left(\mathrm{Y}_{\mathrm{i}}\right)$, we applied the models that took the following values for an i-th respondent:

$$
Y_{i}=\left\{\begin{array}{cc}
1 & \text { if a respondent used social media as data and information source } \\
0 & \text { otherwise }
\end{array}\right.
$$

Since the variables are nominal, logit models were used. A binary choice logit model takes the following form (Greene, 2002):

$$
P\left(Y_{i}=1 \mid m\right)=\Lambda\left(m^{\prime} \alpha\right)=\frac{\exp \left(m^{\prime} \alpha\right)}{1+\exp \left(m^{\prime} \alpha\right)} .
$$

where: $\Lambda\left(m^{\prime} \alpha\right)$ - logistic cumulative distribution function, $m$-vector of explanatory variables, $\alpha$-vector of parameters, and $\mathrm{i}=1, \ldots, \mathrm{N}$-surveyed individuals. Vector $m$ contains basic characteristics of surveyed professionals and institutions represented by them (respondent-specific and firm-specific variables), 
as well as additional variables that will describe how respondents perceive 'information' ('information needs perception' variables - see section 2.3).

To test for statistical significance of the whole set of variables, a likelihood ration (LR) test was used, which has a $X^{2}$ distribution with $k$ degrees of freedom, where $k$ is the number of explanatory variables. We calculated a variance inflation factor (VIF) for each variable (see Table 3 in the Appendix). Collinear variables, most often taken as the benchmark cases, were eliminated. Results confirm that explanatory variables were not significantly correlated among each other.

\subsection{Variables and analysis design}

Our dependent variable - the use of social media for job-related, informational purposes-is nominal (1-used; 0-not used). This variable came from the survey item that asked: 'Which social media listed below do you use as an information source for professional purposes?' (see Appendix for details on the questionnaire). The respondents would choose among seven responses to this question, including 'None' as last response. The selection of 'None' was coded as 0 (1 otherwise).

Independent variables were categorised as follows: (i) firm-specific variables, (ii) respondent-specific variables, (iii) 'information needs perception' variables. Firmspecific variables include firm type (i.e., the categories of financial institutions participating in the study), value of assets under the firm's management (asset_value), diversification of the assets (asset_number), and risk of the assets. We used total experience in business analysis / asset management (exp_general) and practice on current job position (exp_occup)—both measured in full (completed) years_-and job position as respondent-specific variables. Job position was coded as a dummy variable, based on respondents' responses to the following survey item (open-ended question): 'What is your job position in the institution?' (see Table 1 as well as the Appendix for details).

Value of assets under the firm's management came from the survey item that asked: 'Indicate the value of assets under management of the institution you work in (in PLN million)'. Respondents were choosing from four possible ranges to report the value of the assets (see the survey instrument in the Appendix to learn the ranges). They were also allowed to refuse a response to this survey item. Diversity of the assets was estimated with the following survey item: 'Indicate up to three the most important assets managed by the institution you work in'. This was followed by the gamut of asset categories different in terms of their riskreward profiles (from 'Cash and equivalents' to 'Derivatives and other high-risk 
assets') for respondents' selection. The gamut included seven categories of assets (again, the details can be found in the survey instrument in the Appendix), however, as mentioned, the respondents were asked to indicate three categories of assets, at most, which are key in the portfolios held by their institutions. Hence, the asset diversification was coded as the ordinal variable on a scale from 0 (if the respondent reported no asset management activity in her institution) to 3 . Finally, in measuring the riskiness of the assets we considered cash with its equivalents as well as fixed-income assets as safe, while other assets (shares, real-estate, and derivatives) were treated as risky assets. The riskiness of asset portfolio was reported as the respondents' responses (coded as dummy variables) to the following survey item: 'Indicate up to three the most important assets managed by the institution you work in'. Importantly, when running the analyses we noticed that considerable quantity of respondents reported 'Derivatives' (or other exceptionally risky assets)as 'Other' in this survey item. Therefore, we isolated the class of assets for further analyses and marked it 'asset_hrisk' (for 'high-risk assets'). Firm type was used as a dummy variable based on respondents' responses to the following survey item: 'What is the institution you work in?' The question was followed by a set of possible responses, including the option 'Other' (details are given in Table 1 as well as in the Appendix).

The questionnaire featured, among others, the following query: 'Indicate the statements you identify yourself with as to your job'. The responses to the question were used as additional explanatory variables revealing respondents' perception of current information needs in their work. In other words, the responses to the query were designed as a vehicle to get a deepened insight into the forces behind the observed selection patterns concerning the usage of social media. We included the following answers to the question, used as independent variables in the regression models ('information needs perception' variables):

info_change: 'We need different data and information from what we needed a couple of years ago';

info_much: 'The magnitude of data and information is so big that it is hard to work through it';

info_large: 'The advantage is hidden in the analyses of massive amounts of nonhomogenous data and information';

info_visual: 'Visualisation of data and information gains in value'; info_one: 'Despite progress, we lack an all-encompassing database for financial market professionals'. 
Three models (henceforth marked from 1 through 3) were used in the examination of the factors behind social media use as the information source supporting decisions. The models were gradually (incrementally) supplemented by additional explanatory variables. Thus, Model 3 is the most comprehensive, and potentially the most insightful. Model 1 is unique in the sense that it is the only model that includes, except respondent-specific characteristics, asset value and asset diversification as the explanatory variables. The variables were excluded from other models to maintain comparability of results across the entire sample, as only about half of the respondents revealed the asset value in the survey. The results of modelling are presented in Table 2. In Model 1, the sample is halved, being restricted only to the respondents who provided financial information on their assets. Model 2 is expanded by detailed information about surveyed firms, their representatives and types of assets under their management. The sample is whole. In Model 3 we also included 'information needs perception' variables. Finally, in all models, the rationale behind the benchmarks selection was the highest VIF value / $\mathrm{p}$-value.

\section{RESULTS}

Nearly 64\% of surveyed financial market professionals use social media for information purposes. Social networking sites-for example, Facebook and LinkedIn-are the most popular platforms (39.8\%). However, the intensity of social media use among Polish professionals is considerably lower when compared with results from other countries (Bowles, 2010; Greenwich Associates, 2015). Approximately 50\% of respondents use social media once a month or less frequently, and about $17 \%$ of them visit such platforms every day.

\section{Variables}

$\%$

$\mathbf{N}$

Usage of social media (Y)

Social media users

63.9

265

Social media non-users

$36.1 \quad 150$

All

100

415

Job position

Agent / broker / advisor (occup_broker)

Analyst (occup_analyst)

12.0 
Executive, including CEO (occup_executive)

$17.1 \quad 71$

Director / manager (occup_manager)

CFO / accountant (occup_findir)

Specialist (occup_specialist)

$5.1 \quad 21$

Owner (occup_owner)

Other (occup other)

Other (occup_other)

All

1 or less

2-4

$41.7 \quad 173$

5-7

$10.1 \quad 42$

8-10

$12.3 \quad 51$

More than 10

$8.9 \quad 37$

More than 10

No answer

$25.8 \quad 107$

All

$1.2 \quad 5$

$100 \quad 415$

Practice on current job position (in completed years) (exp_occup)

1 or less

2-4

$11.3 \quad 47$

5-7

$27.5 \quad 114$

8-10

20.7

86

12.3

51

More than 10

$26.5 \quad 110$

No answer

$\begin{array}{ll}1.7 & 7\end{array}$

All 
Universal bank (firm_ubank)

Brokerage house (firm_house)

$25.3 \quad 105$

Other brokerage activity (firm_broker)

$6.5 \quad 27$

Investment funds / asset management / private equity / venture capital

$11.8 \quad 49$

(firm_fund)

$6.7 \quad 28$

Insurance company (firm_insurer)

$13.0 \quad 54$

Financial advisory company (firm_advisor)

$10.4 \quad 43$

Other financial institutions (firm_otherfin)

$4.1 \quad 17$

Other (firm_other)

$11.6 \quad 48$

All

Assets under management of the institution (in PLN million) (asset_value)

No asset management

$(0 ; 100]^{*}$

$20.0 \quad 83$

$(100 ; 1,000]$

$14.7 \quad 61$

$(1,000 ; 10,000]$

$9.4 \quad 39$

$(10,000 ;+\infty)$

$3.1 \quad 13$

$4.3 \quad 18$

No answer

$48.4 \quad 201$

All

$100 \quad 415$

Key assets in the managed portfolio (asset_number)**

Cash \& equivalents (asset_cash)

Polish fixed-income assets (asset_pfixed)

Foreign fixed-income assets (asset_ffixed)

$9.6 \quad 59$

3.62

Polish shares (asset_pstock)

Foreign shares (asset_fstock)

Real estate assets (asset_estate)

$6.2 \quad 38$

Other, indicated as Derivatives and other high risk assets (asset_hrisk) 
No asset management

$25.5 \quad 157$

All

\begin{tabular}{|c|c|c|}
\hline \\
\hline & 84.8 & 356 \\
\hline & 51.6 & 214 \\
\hline info_large & 61.9 & 257 \\
\hline & 69.2 & 287 \\
\hline & 56.4 & 234 \\
\hline
\end{tabular}

Note: $* 100$ EUR $=429$ PLN on the day of the article submission; $* *$ Respondents were permitted to select maximum three types of assets; ***Respondents were permitted to select any number of answers. Source: Authors`elaboration

Table 1. Variables used in the regression models and their codes

Respondents were free to select from the list of options when answering the question: 'Which social media listed below do you use as an information source for job-related purposes?' The list included the following: (i) discussion forums / Q\&A portals, (ii) blog, (iii) microblog (including Twitter), (iv) social networks (e.g., Facebook or LinkedIn), (v) social news platforms, (vi) other (which?), and (vii) none. Nearly $11 \%$ of respondents found the range of options for selection in the questionnaire incomplete and indicated other media not featured by us in the cafeteria. Furthermore, the results show that social media are not exploited intensively by those respondents who reported they were the users of such media. Almost 50\% acknowledged that they use it at most once a month or less often. Interestingly, everyday users comprised the second largest group (slightly less than $17 \%$ ), yet are substantially smaller in number compared to the most occasional users.

In order to test $\mathrm{H} 1$ and $\mathrm{H} 2$, we examined whether the value of assets under the firm's management and diversification of the assets have an impact on social media use for information purposes. In Model 1, the number of assets (H2) has a positive impact on social media use among financial market professionals in Poland [p $<0.05]$. However, the value of assets (H1) is not a significant factor influencing the dependent variable [p $>0.05]$. 
We tested H3 by investigating whether the risk related to assets included in a firm's portfolio affects social media use for information purposes. In Model 2, this relationship is found to be significantly positive [p < 0.05], however only for the class of the most risky assets (i.e. derivatives and other high risk assets, labelled as asset_hrisk in the analysis). Companies that managed these exceptionally risky assets were significantly more likely to use social media than others. Interestingly, similar positive and significant relationship was observed for real estate assets (asset_estate). Model 3 confirmed such results.

Finally, to test H4, we examined the effect of general work experience and job experience gained from a company's position on social media use for information purposes. Model 1 shows that both factors have no significant impact on the dependent variable [p $>0.05]$. In other words, there is no relationship between a respondent's job experience (general and present) and social media use for information purposes.

In terms of the job position, the executives (including CEO) and analysts were the only groups with statistically significant results. In both cases, they evidence a lower likelihood of switching to social media as data and information sources as compared to the benchmark group (directors and managers).

Model 3 was augmented by additional factors that reflect the way financial market professionals perceive current situation in the market for data and information (i.e., 'information needs perception' variables). The only view significantly associated with social media usage was that 'visualisation of data and information gains in value', an observation rather invaluable in light of what was hypothesised in the study. Nevertheless, this finding supports the claims of other authors pointing out to the benefits embedded in the performance (visualisation) dashboards (Velcu-Laitinen and Yigitbasioglu, 2012).

\begin{tabular}{lllllll}
\hline \multicolumn{1}{c}{ Variable } & \multicolumn{2}{c}{ Model 1 } & \multicolumn{2}{c}{ Model 2 } & \multicolumn{2}{c}{ Model 3 } \\
& Effect & SE & Effect & SE & Effect & SE \\
exp_occup & -0.022 & $(0.107)$ & -0.125 & $(0.086)$ & -0.097 & $(0.088)$ \\
exp_general & -0.086 & $(0.086)$ & -0.053 & $(0.073)$ & -0.061 & $(0.074)$ \\
asset_value & -0.046 & $(0.101)$ & & & & \\
asset_number & 0.405 & $(0.172)^{* *}$ & & & & \\
\hline
\end{tabular}




\begin{tabular}{|c|c|c|c|c|}
\hline firm_fund & 0.086 & $(0.599)$ & 0.207 & $(0.611)$ \\
\hline firm_house & 0.207 & $(0.582)$ & 0.354 & $(0.597)$ \\
\hline firm_insurer & -0.366 & $(0.478)$ & -0.385 & $(0.483)$ \\
\hline firm_advisory & 0.432 & $(0.501)$ & 0.563 & $(0.513)$ \\
\hline firm_otherfin & 0.520 & $(0.755)$ & 0.632 & $(0.763)$ \\
\hline firm_ubank & -0.563 & $(0.410)$ & -0.614 & $(0.413)$ \\
\hline firm_broker & 0.380 & $(0.486)$ & 0.353 & $(0.491)$ \\
\hline firm_other & 0.681 & $(0.529)$ & 0.651 & $(0.536)$ \\
\hline occup_analyst & -1.083 & $(0.581)^{*}$ & -1.156 & $(0.594)^{*}$ \\
\hline occup_executive & -0.648 & $(0.377)^{*}$ & -0.712 & $(0.385)^{*}$ \\
\hline occup_specialist & -0.001 & $(0.532)$ & -0.071 & $(0.537)$ \\
\hline occup_broker & -0.358 & $(0.370)$ & -0.434 & $(0.376)$ \\
\hline occup_findir & -0.086 & $(0.588)$ & 0.015 & $(0.602)$ \\
\hline occup_owner & 0.013 & $(0.348)$ & -0.038 & $(0.355)$ \\
\hline occup_other & 1.706 & (1.128) & 1.577 & (1.133) \\
\hline asset_pfixed & 0.548 & $(0.386)$ & 0.472 & $(0.390)$ \\
\hline asset_ffixed & 0.399 & $(0.574)$ & 0.362 & $(0.578)$ \\
\hline asset_pstock & 0.532 & $(0.363)$ & 0.524 & $(0.366)$ \\
\hline asset_fstock & -0.201 & $(0.464)$ & -0.147 & $(0.476)$ \\
\hline asset_estate & 0.894 & $(0.423)^{* *}$ & 0.909 & $(0.427)^{* *}$ \\
\hline asset_hrisk & 0.930 & $(0.347)^{* * *}$ & 0.905 & $(0.354)^{* *}$ \\
\hline info_change & & & 0.267 & $(0.339)$ \\
\hline
\end{tabular}




$$
\begin{aligned}
& \text { info_much } \\
& \text { info_large } \\
& \text { info_visual } \\
& \text { info_one } \\
& \text { N }
\end{aligned}
$$$$
200
$$$$
407
$$

BIC

$$
299.3
$$

HQ

$\%$ predicted

$$
63.8
$$

69
658.1

$-0.232 \quad(0.235)$

$0.451 \quad(0.262)^{*}$

$0.143 \quad(0.235)$

407

587.9

68.3

LR $\chi^{2}$

$$
8.4[0.08]^{*} \quad 43.9[0.01]^{* *}
$$

$49.7[0.01]^{* *}$

Note: Standard errors in parentheses, p-values in square brackets. * means significant at 0.1 , ** means significant at $0.05, * * *$ means significant at 0.01 . Constants were included in the models, but omitted in the table. In the case of each variable VIF $<3$.

Source: Authors`elaboration.

Table 2. The regression analysis results

\section{DISCUSSION}

Overall, our results do not confirm findings of some previous research suggesting that searching for information on social media is becoming popular among financial market professionals (ABA's Endorsed Solutions Group, 2015; Kouri and Bowen, 2015). Polish financial market professionals tend to retrieve such information occasionally, although some company features and user characteristics may increase the likelihood of social media use for information purposes. This may be explained by the fact that social media content is often untreated, redundant, and less credible than content provided by other sources, especially by such renowned analytical firms such as Bloomberg or Reuters (Power and Phillips-Wren, 2011). 
Another explanation is the 'time lag effect' observed in the finance industry. It is probable that the industry's embracing of social media will increase as analytical methods designed to process and interpret information retrieved from social media will improve, and firms will adjust their 'intelligence systems' to a new market reality co-shaped by social media. Such explanation is supported by opinions gathered through surveys carried out by DVFA - IR Club (2015) and Greenwich Associates (2015), showing that a majority of finance professionals believe that social media will play an increasingly important role as a lever of investment decisions in the future. Additionally, the aforementioned 'time lag' can be partly explained by the presumable waiting stance assumed by the institutional investment community: the professionals can wait for more unambiguous results of the empirical examination of data mining techniques aimed at extraction of the incremental content (e.g., in the form of investor sentiment) from social media. So far, the findings in this field are inconclusive (Sprenger and Welpe, 2013; Chen et al. 2012; Antweiler and Frank, 2004; Kim and Kim, 2014). Paradoxically, without such clear-cut empirical confirmation, the inclusion of social media into the sources routinely monitored by financiers can rather hinder analyses than facilitate them due to a kind of 'cognitive cacophony' and decisional paralysis that it engenders. In such cases, social media can act like a 'data smog' diffuser, impeding decisions instead of making them more effective. Moreover, some finance professionals can suspect that the informational signals conveyed by social media are somewhat manipulated by Internet bots or paid analysts. The spread of fake or misleading information about particular stocks was the subject of an Investor Alert issued by the U.S. Securities and Exchange Commission (SEC, 2014). It is more than likely that such concerns, reinforced by the high costs of mitigating them, will preclude them from reaching for social media content.

Despite the problems discussed above, our study showed that a proportion of financial market professionals use social media platforms for data and informational purposes. Social networking sites along with Q\&A portals were the most popular information sources in our study (each was indicated by slightly less than $40 \%$ of the total sample). This is consistent with earlier findings in which the surveyed representatives of financial institutions ranked social networking sites as their number one media (Greenwich Associates, 2015; Kouri and Bowen, 2015). Remarkably, Twitter, alongside other microblogs, is used by a materially smaller percentage of financial market professionals (14\%) compared to other social 
media. This seems to be part of a 'European effect' since Twitter is visibly less popular in Europe than the USA, a phenomenon documented in other sources (Greenwich Associates, 2015). Also, our study indicates possible poor understanding of the term 'social media' on the part of respondents as they pointed out news media online (i.e., not social media) - bankier.pl, interia.pl, onet.pl - in response to our invitation to add categories absent in the provided list. Their additions also suggest that in some firms internal social media are in use.

We found that respondents representing companies with assets generating the highest levels of risk are using social media more frequently. As we expected, more risky assets in a company's portfolio may encourage financial market professionals to search for additional information sources, optimising the decision-making process. However, such effect was documented only for the highest-risk class of assets (i.e. derivatives).This appears to be convergent with some prior research (Chen et al., 2014), and may further suggest that the most risky assets generate undesirable costs exceeding operational costs produced by processing information retrieved from social media.

It is also evident that there is a relationship between the diversification of assets in a company's portfolio and social media use for information purposes. At the same time, the value of assets has no impact on the dependent variable. Such results may suggest that more mixed assets reflect a decisional complexity for financial market professionals. In other words, more diverse assets require more complex and wider market information, which encourages respondents to use social media platforms, such as Facebook, LinkedIn, or Twitter.

Finally, among respondent-specific variables, both experience measures (exp_occup and exp_general) were found to be statistically insignificant. This insignificance may be, to some extent, due to a respondent age bias, as older respondents may use social media less often than others. Although insignificant, the use of social media was inversely dependent on the years of experience: the more experienced respondents, the lower the probability of using social media. Additionally, we found no association between job position and social media use among financial market professionals in Poland. Of a wide array of occupations that were examined, only executives and analysts appear to be more inclined towards social media as an information source. These combined findings can suggest that an effect of 'overconfidence' is not related to financial market professionals with greater job experience. Social media is, rather, used by 
information-dependent respondents searching for additional sources, helping them to optimise the decision-making process.

\section{CONCLUSIONS}

Considering that social media can support financial market professionals by delivering supplementary decision-relevant content, we were curious about the interest of the finance community in monitoring the content. The results brought by our survey are intriguing in this respect. Although they show that almost twothirds of the sample used social media for data and information provision purposes, it was more like testing rather than natural and routine, everyday usage. The majority of surveyed financial professionals reported that they used social media more or less occasionally. Expectedly, the applied regression models revealed that the likelihood of embracing social media for supporting their decisions was higher in institutions with more diversified assets in the portfolios under their management and in those that managed the most risky financial instruments. By contrast, respondent-specific factors turned out to be statistically insignificant in explaining social media usage for informational purposes.

Such findings can be interpreted in a variety of ways. Firstly, they can suggest that what we observe nowadays is wariness typical for the early stages of change implementation. If so, then the future will reveal the genuine value of social media content in terms of its ability to inform financial market professionals. Secondly, the results presented in the paper may mean that the professionals are aloof towards information content of social media, as they do not consider it credible, or, alternatively, easily convertible into money. Regardless of the interpretation, the outcomes of our study are consistent with the general conclusions of sentiment analysis literature pointing out that, despite its theoretical utility, practical usefulness of social media-derived content is below expectations, at least so far. Perhaps, financial market professionals will track scholarly developments in the field and from them take an expectant stance.

Also, from the empirical evidence demonstrated in the study, one can conclude that there are some shortcomings in the understanding of the social media sphere by financial market professionals. It seems that they do not have a good understanding of the media, and, hence, they may not affirm the potential rooted in it.

Considering that the issue of social media as an emerging information source has been neglected as a research problem so far, our study fills a gap in the knowledge 
on how financial market professionals provide themselves with information retrieved from these media and - although indirectly - what is their comprehension of this sphere. As proved by earlier studies, financial market professionals are constantly becoming better informed. Our research contributes to the body of evidence by showing the way social media can alter the patterns of business information acquisition.

\subsection{Limitations and future research}

The number of social media users evidenced by our study (almost 64\%) is significantly smaller when compared with foreign studies (Bowles, 2010; Greenwich Associates, 2015). However, such comparisons can be questioned because of the differences in the research tools (e.g., survey design). To minimise the number of refusals in the survey, we reduced the quantity of questions to those having the greatest projected cognitive potential. As a result, many interesting questions remained unasked. Future surveys could include direct inquiries concerning the motivation behind using, or, alternatively, not using social media for data and informational purposes. Also, our findings evidenced that the social media savvy can be low in large samples of finance professionals. Hence, it would be interesting to study their knowledge and understanding of the media, the gaps in this field that could be potentially useful in explaining the attitudes towards social media, and, ultimately, the reasons behind the decision to use them.

Our findings show that a company's characteristics may have an impact on social media use by financial market professionals. However, such association can be a country-specific effect and may have only local character. Hence, the findings cannot be generalised to a wider population of firms from Europe or worldwide. It is, therefore, reasonable to conduct similar research in other countries to test whether selected characteristics have an impact on decisions to use social media as an information source.

Finally, our regression results showing that the extent to which the dependent variable was explained by adapted independent variables varied between $63.8 \%$ and $69 \%$ indicate that future research should test other, potentially explanatory variables not included by us.

\section{Acknowledgements}

Kamil Filipek thanks the National Science Centre (NCN) Poland for support through Grant No. 2014/12/S/HS6/00390. 


\section{REFERENCES}

ABA'S ENDORSED SOLUTIONS GROUP (2015): The state of social media in banking. American Bankers Association. http://www.aba.com/Products/Endorsed/ Documents/ABASocialMedia_Report.pdf.

ANTWEILER, W.; FRANK, M.Z. (2004):“Is all that talk just noise? The information content of internet stock message boards”, Journal of Finance,vol. 59 n. 3: 1259-1294.https://doi.org/10.1111/j.1540-6261.2004.00662.x

ARROW, K.J. (1985):“The economics of agency”, In J.W. Pratt, R. Zechkauser (Eds.). Principals and agents: The structure of business. Harvard Business School Press, Boston.

BARBER, B. M.; ODEAN, T. 2002. "Online investors: Do the slow die first?” Review of Financial Studies, vol. 15, n. 2: 455-487. http://doi.org/10.2139/ssrn.219242.

BING, L.; CHAN, K.C.C.; OU, C. (2014): "Public sentiment analysis in twitter data for prediction of a company's stock price movements”, In Proceedings - 11th IEEE International Conference on E-Business Engineering, (ICEBE): 232-239. https://doi.org/10.1109/ICEBE.2014.47.

BOLLEN, J.; MAO, H.; ZENG, X.(2011):“Twitter mood predicts the stock market”, Journal of Computational Science,vol. 2, n. 1: 1-8. https://doi.org/10.1016/j.jocs.2010.12.007.

BOWLES, P.(2010): Social networking for market professionals: How is it changing the face of financial markets. Thomson Reuters. http://www.sl ideshare.net/markhaywardjones/social-networks-and-the-financial-markets.

BOYD, D.; ELLISON, N.B.(2008):“Social network sites: Definition, history, and scholarship”, Journal of Computer-Mediated Communication,vol. 13: 210-230. https://doi.org/10.1111/j.1083-6101.2007.00393.x.

CAO, X.; GUO, X.; VOGEL, D.R.; LIU, H.; GU, J. (2012):“Understanding the influence of social media in the workplace: An integration of media synchronicity and social capital theories”,In Proceedings of the Annual Hawaii International 
Conference on System Sciences (pp. 3938-3947). https://doi.org/10.1109/ HICSS.2012.618.

CHANDA, R.; ZAORSKI, S.(2013):"Social media usage in the financial services industry: Toward a business-driven compliance approach”, Journal of Taxation and Regulation of Financial Institutions, vol. 26, n. 5: 5-20.

CHEN, H.; DE, P.; HU, Y.; HWANG, B.H. (2012):“Customers as advisors: The role of social media in financial markets”, SSRN Electronic Journal.https://doi.org/10.2139/ssrn.2024086.

CHEN, H.; DE, P.; HU, Y.; HWANG, B.H. (2014):“Wisdom of crowds: The value of stock opinions transmitted through social media”, Review of Financial Studies,vol. 27, n. 5: 1367-1403. https://doi.org/10.1093/rfs/hhu001.

CUMMING, C.M.; HIRTLE, B.J.(2001):“The challenges of risk management in diversified financial companies”, Economic Policy Review, vol. 7, n. 1: 1-17.

DONG, W.; LIAO, S.S.; XU, Y.; FENG, X.(2016):"Leading effect of social media for financial fraud disclosure: A text mining based analytics”, Paper presented at the 22nd Americas Conference on Information System, 10-14 August 2016, San Diego, USA.

DVFA - IR CLUB(2015): The use of social media by European investment professionals. Social Media Survey 2015. Deutsche VereinigungfürFinanzanalyse und Asset Management. http://www.dvfa.de/fileadmin/downloads/Publikationen/ Umfragen/DVFA_IRClub_Social_Media_Survey_2015.pdf.

FAN, W.; GORDON, M.D.(2013):”The power of social media analytics”, Communications of the ACM, vol.57, n. 6: 74-81. https://doi.org/ $10.1145 / 2602574$.

FUCHS, C.(2015):“Culture and economy in the age of social media”. New York: Routledge. https://doi.org/10.4324/9781315733517.

GNIP(2014): Social media in financial markets: The coming of age... Gnip Whitepaper.http://stocktwits.com/research/social-media-and-markets-the-comingof-age.pdf. 
GREENE, W.H. (2002):“Econometric analysis. 5th ed.” Upper Saddle River, New Jersey: Prentice Hall.

GREENWICH ASSOCIATES(2015): Institutional investing in the digital age: How social media informs and shapes the investing process. Greenwich Associates.https://www.greenwich.com/sites/default/files/reports_pdf/IS-Digital_ Media-2015-GR.pdf.

GROSSMAN, S.J.; STIGLITZ, J.E.(1980):“On the possibility of informationally efficient markets”, The American Economic Review, vol. 70, n. 3: 393-408. https://doi.org/10.1111/jeea.12107.

GUISO, L.; JAPPELLI, T.(2006): Information acquisition and portfolio performance. Centre for Studies in Economics and Finance. Working Paper No. 167. University of Salerno, Italy. http://www.csef.it/WP/wp167.pdf.

HOBDAY M.; CHARLES, S. (2012): "Rebuilding Customer Trust in Retail Banking. IBM Financial Services Sector: Thought Leadership White Paper”: Retrieved from https://www-935.ibm.com/services/multimedia/ IBM1049_Trust_ White_Paper_05.pdf.

HU, T.; TRIPATHI, A.(2016):“Impact of social media and news media on financial markets”, Paper presented at the 37th International Conference on Information Systems, 11-14 December 2016, Dublin, Ireland. http://ssrn.com/abstract=2796906.

KAPLAN, A.M.; HAENLEIN, M.(2010):“Users of the world, unite! The challenges and opportunities of Social Media”, Business Horizons,vol. 53: 59-68. https://doi.org/10.1016/j.bushor.2009.09.003.

KELLER, J.; PASTUSIAK, R.(2016):“The psychology of investing: Stock market recommendations and their impact on investors' decisions (the example of the Polish stock market)”, Acta Oeconomica,vol. 66, n. 3: 419-437. https://doi.org/10.1556/032.2016.66.3.3.

KIM, S.H.; KIM, D.(2014): "Investor sentiment from Internet message postings and predictability of stock returns”, Journal of Economic Behavior and Organization,vol. 107 (Part $\quad$ B): 708-729. https://doi.org/10.1016/j.jebo. 2014.04.015. 
KIRCHLER, M.(2010):"Partial knowledge is a dangerous thing. On the value of asymmetric fundamental information in asset markets”, Journal of Economic Psychology, vol. 31, n. 4: 643-658. https://doi.org/10.1016/j.joep.2010.04.005.

KOMISJA NADZORU FINANSOWEGO (2016). https://www.knf.gov.pl/ podmioty/ Rejestry_i_Ewidencje.

KOURI, L.; BOWEN, B.(2015): 2015 Financial professionals social media adoption study. American Century Investments.

LEADTAIL - INTACCT (2015): CFOs \& Finance Leaders 2015. How CFOs engage with people, brands, and content on Twitter. Social Insight Report. Leadtail - Intacct. http://www.slideshare.net/Leadtail/cfos-on-social-media-socialinsights-report.

LEFTHERIOTIS, I.; GIANNAKOS, M. N. (2014): "Using social media for work: Losing your time or improving your work?”, Computers in Human Behavior, vol. 31, n. 1), 134-142. https://doi.org/10.1016/j.chb.2013.10.016

LUO, X.; ZHANG, J.; DUAN, W.(2013):“Social media and firm equity value”, Information Systems Research, vol. 24, n. 1: 146-163. https://doi.org/10.1287/ isre.1120.0462.

MARTINSSON, J.; DAHLBERG, S.; LUNDMARK, S. O. (2013): “Is accuracy only for probability samples? Comparing probability and non-probability samples in a country with almost full internet coverage”. Paper presented at the 68th Annual Conference of the American Association for Public Opinion Research, 1519 may 2013, Boston, MA. https://lore.gu.se/digitalAssets/1455/1455221_ martinsson--dahlberg-and-lundmark--2013--aapor-is-accuracy-only-for-probabilit y-samples.pdf.

MEIJER, A.; THAENS, M. (2013): "Social media strategies: Understanding the differences between North American police departments”, Government Information Quarterly, vol. 30, n. 4: 343-350. https://doi.org/10.1016/j.giq. 2013.05.023.

MEIKLE, G. (2016):"Social media. Communication, sharing and visibility. 1st ed.” London: Routledge. https://doi.org/10.4324/9781315884172. 
NAIR, M.(2011):“Understanding and measuring the value of social media”, The Journal of Corporate Accounting \& Finance, vol. 22, n. 3: 45-51. https://doi.org/10.1002/jcaf.20674.

NBP (2016): Rozwój system finansowego w Polsce w 2015 r. (eng. The growth of financial system in Poland in 2015). National Bank of Poland. https://www.nbp.pl/systemfinansowy/rozwoj2015.pdf.

OBAR, J.A.; WILDMAN, S.(2015):“Social media definition and the governance challenge: An introduction to the special issue”, Telecommunications Policy,vol. 39: 745-750. https://doi.org/10.1016/j.telpol.2015.07.014.

POWER, D.J.; PHILLIPS-WREN, G.(2011):“Impact of social media and Web 2.0 on decision-making”, Journal of Decision Systems, vol. 20, n. 3: 249-261. https://doi.org/10.3166/jds.20.249-261.

RAVICHANDRAN, T.; LERTWONGSATIEN, C. (2005):"Effect of information systems resources and capabilities on firm performance: A resource-based perspective”, Journal of Management Information Systems, vol. 21, n. 4: 237-276. https://doi.org/10.1080/07421222.2005.11045820.

ROBEHMED, N. (2012): Financial services: More than customer service online. Forbes. https://www.forbes.com/sites/natalierobehmed/2012/04/17/rt-financialservices-more-than-customer-service-online/\#2aec0253667e.

SCHNIEDERJANS, D.; CAO, E.S.; SCHNIEDERJANS, M. (2013): “Enhancing financial performance with social media: An impression management perspective”, Decision Support Systems, vol. 55, no. 4: 911-918. https://doi.org/10.1016/j.dss.2012.12.027.

SEC (2014): Investor alert: Social media and investing - stock rumors. U.S. Securities and Exchange Commission. http://investor.gov/news-alerts/investoralerts/investor-alert-social-media-investing-stock-rumors\#.U9e1blaInGA.

SHENK, D. (1998):“Data smog. Surviving the information glut”. NewYork: HarperCollins Publishers. 
SPRENGER, T.O.; WELPE, I.M. (2013):“Tweets and trades: The information content of stock microblogs”, European Financial Management,vol. 20, n. 5: 926957. https://doi.org/10.1111/j.1468-036x.2013.12007.x.

TÓTH, B.; SCALAS, E. (2008):“The value of information in financial markets: An agent-based simulation”, In J. Huber, M. Hanke (Eds.). Information, Interaction, and (In) Efficiency in Financial Markets. Vienna: Linde Verlag.

VELCU-LAITINEN, O.; YILGLITBASIOGLU, O.M. (2012):“The use of dashboards in performance management: Evidence from sales managers”, The International Journal of Digital Accounting, vol. 12: 36-58. https://doi.org/10.4192/1577-8517-v12_2.

ZHANG, L.; XIAO, K.; LIU, Q.; TAO, Y.; DENG, Y. (2016):“Modeling social attention for stock analysis: An influence propagation perspective”, Paper presented at the 15th IEEE International Conference on Data Mining, 14-16 November 2015, Atlantic City, USA, 609-618. https://doi.org/10.1109/ icdm.2015.117. 


\section{Appendix}

Survey instrument

Which social media listed below do you use as an information source for professional purposes?

Discussion forums / Q \& A portals

Blogs

Microblogs (Including Twitter)

Social networks (e.g. Facebook or LinkedIn)

Social news platforms

Other (which?)

None

How often do you use social media as an information source for professional purposes?

Everyday

3-4 times weekly

1-2 times weekly

Less frequently than one weekly, but more frequently than one monthly

Less frequently than once monthly

Indicate the statements you identify yourself with as to your job:

We need different data and information from what we needed a couple of years ago

The magnitude of data and information is so big that it is hard to work through it

The advantage is hidden in the analyses of massive amounts of non-homogenous data and information

Visualisation of data and information gains in value

Despite progress, we lack an all-encompassing database for financial market professionals 
What is the institution you work in?
a. Universal bank
b. Investment bank
c. Brokerage house
d. Other brokerage activity
e. Investment funds / Asset management / Private equity / Venture capital
f. Insurance company
g. Finance advisory company
h. Other financial institutions
i. $\quad$ Other

What is your job position in the institution? (Open question)

Since when you are on the position (in completed years)?
a. 1 or less
b. 2-4
c. $5-7$
d. $8-10$
e. More than 10
f. No answer

How long have you been working with listed companies analytics or / and asset management (in completed years)?
a. 1 or less
b. $2-4$
c. $5-7$
d. $8-10$
e. More than 10
f. No answer

Indicate the value of assets under management of the institution you work in (in PLN million).
a. $(0 ; 100]$
b. $(100 ; 1,000]$
c. $(1,000 ; 10,000]$
d. $(10,000 ;+\infty)$
e. No answer

Indicate up to three the most important assets managed by the institution you work in.
a. Cash \& equivalents
b. Polish fixed-income assets
c. Foreign fixed-income assets
d. Polish shares
e. Foreign shares
f. Real-estate assets
g. Other
h. No asset management 


\begin{tabular}{|c|c|c|c|}
\hline Variable & Model 1 & Model 2 & Model 3 \\
\hline exp_occup & 1.066 & 1.195 & 1.303 \\
\hline exp_general & 1.046 & 1.271 & 1.345 \\
\hline asset_value & 1.552 & & \\
\hline asset_number & 1.551 & & \\
\hline firm_fund & & 1.746 & 1.936 \\
\hline firm_house & & 1.696 & 1.822 \\
\hline firm_insurer & & 2.331 & 2.502 \\
\hline firm_advisory & & 1.984 & 2.136 \\
\hline firm_otherfin & & 1.440 & 1.514 \\
\hline firm_ubank & & 2.747 & 2.927 \\
\hline firm_broker & & 2.172 & 2.377 \\
\hline firm_other & & 2.234 & 2.444 \\
\hline occup_analyst & & 1.282 & 1.342 \\
\hline occup_executive & & 1.703 & 1.805 \\
\hline occup_specialist & & 1.258 & 1.316 \\
\hline occup_broker & & 1.273 & 1.423 \\
\hline occup_findir & & 1.279 & 1.366 \\
\hline occup_owner & & 1.408 & 1.548 \\
\hline occup_other & & 1.119 & 1.181 \\
\hline asset_pfixed & & 1.455 & 1.541 \\
\hline asset_ffixed & & 1.278 & 1.352 \\
\hline
\end{tabular}




\begin{tabular}{lcc} 
asset_pstock & 1.570 & 1.635 \\
asset_fstock & 1.440 & 1.553 \\
asset_estate & 1.118 & 1.191 \\
asset_hrisk & 1.118 & 1.182 \\
info_change & & 1.302 \\
info_much & & 1.220 \\
info_large & & 1.234 \\
info_visual & & 1.363 \\
info_one & & 1.160 \\
\hline
\end{tabular}

Table 3. Collinearity results - the variance inflation factors (VIF) 